\title{
Strategic behavior in repeated voluntary contribution experiments
}

Citation for published version (APA):

Mengel, F., \& Peeters, R. J. A. P. (2009). Strategic behavior in repeated voluntary contribution experiments. METEOR, Maastricht University School of Business and Economics. METEOR Research Memorandum No. 025 https://doi.org/10.26481/umamet.2009025

Document status and date:

Published: 01/01/2009

DOI:

10.26481/umamet.2009025

Document Version:

Publisher's PDF, also known as Version of record

\section{Please check the document version of this publication:}

- A submitted manuscript is the version of the article upon submission and before peer-review. There can be important differences between the submitted version and the official published version of record.

People interested in the research are advised to contact the author for the final version of the publication, or visit the DOI to the publisher's website.

- The final author version and the galley proof are versions of the publication after peer review.

- The final published version features the final layout of the paper including the volume, issue and page numbers.

Link to publication

\footnotetext{
General rights rights.

- You may freely distribute the URL identifying the publication in the public portal. please follow below link for the End User Agreement:

www.umlib.nl/taverne-license

Take down policy

If you believe that this document breaches copyright please contact us at:

repository@maastrichtuniversity.nl

providing details and we will investigate your claim.
}

Copyright and moral rights for the publications made accessible in the public portal are retained by the authors and/or other copyright owners and it is a condition of accessing publications that users recognise and abide by the legal requirements associated with these

- Users may download and print one copy of any publication from the public portal for the purpose of private study or research.

- You may not further distribute the material or use it for any profit-making activity or commercial gain

If the publication is distributed under the terms of Article $25 \mathrm{fa}$ of the Dutch Copyright Act, indicated by the "Taverne" license above, 


\section{Maastricht University}

Friederike Mengel, Ronald Peeters

Strategic behavior in repeated voluntary contribution experiments

$\mathrm{RM} / 09 / 025$

\section{METEOR}

Faculty of Economics and Business Administration Maastricht Research School of Economics

of Technology and Organization

\section{P.O. Box 616}

NL - 6200 MD Maastricht

The Netherlands 


\title{
Strategic behavior in repeated voluntary contribution experiments*
}

\author{
${\text { Friederike } \text { Mengel }^{\dagger} \quad \text { Ronald Peeters }}^{\dagger}$
}

June 2009

\begin{abstract}
We conduct a repeated VCM (voluntary contribution mechanism) experiment using the strategy method. We compare a partner and a stranger design and find that participants in the partner treatment provide (i) higher initial contributions, (ii) higher contributions on average over all periods, and (iii) contributions that do not vary more strongly with past contributions than participants in the stranger treatment. We conclude from our evidence that strategic motives can account for a large share of the treatment differences typically observed in this literature.
\end{abstract}

JEL Classification Codes: C90; D01; D74.

Keywords: Public goods; Voluntary contributions; Experiment.

${ }^{*}$ We thank Philipp Reiss, Ernesto Reuben, Martin Strobel and seminar participants at Maastricht University for helpful comments.

${ }^{\dagger}$ Department of Economics, Maastricht University, PO Box 616, 6200 MD Maastricht, The Netherlands. E-mail: \{f.mengel, r.peeters\}@maastrichtuniversity.nl. R. Peeters is financially supported by the NWO. 


\section{Introduction}

We conducted a repeated VCM experiment with a random ending rule in a strategy method (Selten, 1967). Subjects were asked to provide a full description of their behavior in unitrecall strategies. That is, subjects had to provide (1) their initial contribution and (2) their dynamic response contribution conditioned on any possible average contribution by others in the previous period. Our only treatment variable is the matching protocol. In one session the subjects were exposed to a partner matching (group composition remained the same throughout the experiment); in the other to a stranger matching (group composition randomly changed from period to period).

VCM mechanisms and the relation to the matching protocol have been studied extensively in the literature. Most experiments though do not use the strategy method. An early study is Andreoni (1988). He examines the role of learning and strategic behavior as explanations for the decay in contributions that is typically observed in (finitely) repeated VCM experiments. He adopts a stranger condition and a partner condition and implemented a surprise restart in both conditions. The learning hypothesis states that behavior in the final period should not be different in both conditions. The strategic behavior hypothesis implies that partners should contribute more than strangers. Strikingly strangers are found to contribute more than partners over all periods (including the final one). Therefore, both the learning and the strategic behavior hypotheses had to be rejected.

It has been proven difficult to replicate the result that strangers contribute more than partners. ${ }^{1}$ Moreover, after the surprise restart the contributions by partners increased structurally whereas for strangers the contributions went back to the original level rather quickly. Apparently subjects do recognize the impact of their contributions on future contributions by their partners, and hence behave strategically. According to Sonnemans et al. (1999) "the role of strategic behavior in public good games is [still] unresolved".

Sonnemans et al. (1999) used an interesting design to investigate strategic behavior. Group compositions gradually changed by switching two subjects after a certain amount of periods (minimum of three and maximum of twelve). Prior to any decision making, all subjects were informed when a switch would take place in their group and whether they were switched themselves or one of the group members. In either case, partners who were drifted apart would never meet again. The authors find that contributions decline when a change is approaching, and that subjects that are about to leave a group temporarily decrease their contribution. This finding provides evidence for the important role of strategic (forward looking) behavior. They also elicit beliefs on the expected contribution by others and find that subjects with higher

\footnotetext{
${ }^{1}$ Palfrey and Prisbrey (1996) also find that strangers contribute more. Croson (1996), Sonnemans et al. (1999) and Keser and van Winden (2000), among others, find that partners contribute more. Weimann (1994) finds no significant difference. Andreoni and Croson (2008) provide a discussion of the literature comparing contributions by partners and strangers. In a indefinitely repeated two-player prisoner's dilemma, Duffy and Ochs (2009) found that partners contribute more.
} 
expectations contribute more, and conclude that this is evidence for adaptive (backward looking) behavior as beliefs are highly correlated with past observations.

Keser and van Winden (2000) focus on conditional cooperation and distinguish between future-oriented (strategic) behavior and simple reactive behavior. Future-oriented behavior includes aspects of subjects' behavior that are induced by their perception of future interaction and explains higher initial contributions and endgame effects in the partner setting. Simple reactive behavior assumes behavior to be oriented towards the observed average contribution of the other group members in the previous period and includes motives of reciprocity and inequity aversion. Both these latter motives are identified by adaptations of individual contributions towards the group average. They find evidence of both types of conditional cooperation playing a role. Moreover, they argue that the higher contribution in the partner treatment is largely due to the higher initial contribution.

In a repeated sequential prisoner's dilemma setting, Reuben and Suetens (2009) differentiate between endgame behavior and continuation behavior. They find that the endgame effect is mainly caused by strategically cooperating individuals and conclude that the main motive for cooperation is strategic.

The advantage of using the strategy method for the repeated game is that we can disentangle initial contributions from dynamic responses and hence control for path dependencies. Our design also enables us to gain insight into the question of whether it is mainly strategic consideration or mainly reciprocity that drives behavior or others. This is an utterly important question since it enables us to understand to which extent people understand the strategic implications of repeated interactions and react to them in a way predicted by theory. Both reciprocity and the strategic hypothesis predict higher contributions on the induced path in the partner than in the stranger setting. If reciprocity is the driving force then such treatment differences should be mainly reflected in a steeper slope of the dynamic response in the partner treatment, since only in the partner treatment participants have the possibility to directly "reward" high and "punish" low contributions by their partners. Under the strategic hypothesis, on the other hand, treatment differences should be mainly reflected in a higher initial contribution and higher dynamic contributions on average, but not necessarily in a steeper slope.

As in Fischbacher et al. (2001) our design does not allow for learning and hence we check for regret in a post-experimental questionnaire. An advantage of our design with respect to Sonnemans et al. (1999) is that strategic behavior is not triggered by awareness of alternative matching procedures, since we use a between-subjects design.

We find that the initial contributions as well as the mean dynamic response contributions in the partner treatment first-order stochastically dominate those in the stranger treatment. There is no significant treatment difference between the slopes of the dynamic responses. The difference in initial and mean dynamic response contribution cause a substantial different trend in the induced path of contributions which tends to be much higher in the partner 
treatment. Qualitatively the induced paths resemble the trend of contributions found in experiments conducted without the strategy method. ${ }^{2}$ This leads us to conclude that it is mainly strategic motives that drive contributions and that people seem to account well for the repeated nature of the interactions.

The paper is organized as follows. In Section 2 we present the experimental design. Section 3 collects our main results and Section 4 provides a discussion. The instructions for the experiment and some additional graphs and tables can be found in the appendices.

\section{Experimental design and procedures}

In our experiment, participants played a voluntary contribution mechanism (VCM) game. Each of four group members is endowed with 10 tokens and decides how many of these to contribute into a joint project. Every token that is not contributed to the project generates a private income of 2 ECU. In addition, each group member benefits from the joint project. Every token that is contributed to the joint project experiences a return of 4 ECU that is equally divided among the group members (that is: 1 ECU each). Hence, the project has a marginal per capita return of 0.5 .

Participants played the VCM repeatedly. We employed a random ending rule. In each period there was a $90 \%$ chance that the experiment would continue with another period. In the first period participants were randomly and anonymously assigned into groups of size 4 . In the Partner treatment the group composition remained fixed; in the Stranger treatment groups were randomly determined each period anew. Participants were fully informed about all treatment details. For each treatment, we ran one session with 24 participants.

Instead of making a choice in each period, participants were asked to specify their initial contribution and dynamic response behavior. For the dynamic response, participants had to specify their contribution conditional on the average contribution by the (former) group members in the previous period. Next the repeated VCM was simulated by the following iterative process. The initial contributions determined the contributions for the first period. For all remaining periods, the dynamic response behavior was applied. After making their decision participants observed the outcome of these simulations for each period until the end of the experiment. This mechanism (as well as all other details) were carefully explained to all participants in the instructions. ${ }^{3}$

Note that the design does not allow participants to condition their contribution behavior on the full history of realized contributions and time. This is one of the reasons we decided for a random ending rule rather than a fixed ending, since with the fixed ending rule one should

\footnotetext{
${ }^{2}$ Our induced paths are very similar to those found in other public goods experiments with the same incentives. Therefore, we believe that the strategy method did not substantially distort decisions. Also Brandts and Charness (2000) did not find a difference in behavior between a 'hot' and a 'cold' (strategy method) setting for experiments with the prisoner's dilemma and the game of chicken played sequentially.

${ }^{3}$ Instructions are provided in Appendix D.
} 
not expect strategies to be time independent. Still, not allowing participants to condition their contributions on more than just the last observation is restrictive. ${ }^{4}$ There are several reasons why we opted for this restriction to unit-recall strategies. It is the simplest kind of behavior that captures dynamics and hence does not require too much sophistication from participants. Moreover, it allows for a clean, unobstructed analysis of the influence of observed contributions in the past on future contributions and it substantially reduces the dimensionality to classify individuals. Finally, in Fischbacher and Gächter (forthcoming) yesterday's realizations are found to be a highly significant ingredient for today's beliefs.

The experiment was conducted in the experimental laboratory of the faculty of economics and business administration at Maastricht University in March 2009. The experiment was programmed and conducted with the software z-Tree (Fischbacher, 2007). Before the start of a session, subjects read the instructions and were allowed to ask questions that were then individually answered. Afterwards subjects had to answer control questions which tested their understanding of the instructions. One of the experimenters checked the answers and the experiment only started after all subjects answered each question correctly. Subjects earned ECU during the experiment that were converted into Euro at a known exchange rate (one ECU equals three Eurocents) at the end of the experiment. In addition, subjects received a show-up fee of 3 Euro and 2 Euro compensation for answering a post-experimental questionnaire. On average, a session lasted slightly less than 90 minutes. The average payoff was 16.32 Euro.

\section{Results}

Before we start the description of our main results let us set some notation. We denote by $c_{t}^{i}$ the contribution (to the public good) of individual $i$ in (simulated) period $t$. Hence $c_{0}^{i}$ denotes $i$ 's initial allocation. With $\varphi^{i}(\bar{c})$ we denote $i$ 's allocation conditional on average allocation $\bar{c}$. Remember that we elicit only $c_{0}^{i}$ and $\varphi^{i}(\bar{c})$ explicitly and then simulate the induced paths of actual contributions. This has the advantage of producing many independent observations. In fact, we have 24 independent observation in each treatment.

In addition, we would like to point out some evidence from the post-experimental questionnaire. Since we exclude possibilities for learning (by design), we checked whether participants felt any regret after the experiment. After the participants made their choices and observed the induced path of play for 12 (14) periods in the Partner (Stranger) treatment we asked them the following question:

"If you were given the possibility to repeat this experiment. Would you make different decisions in either the initial allocation (first decision screen) or the conditional allocation (second decision screen)? And if so, what would you do different and why?"

\footnotetext{
${ }^{4} \mathrm{~A}$ less restrictive approach has been taken by Keser (2000).
} 
Only $29 \%$ of the participants in the Stranger treatment and $37 \%$ of those in the Partner treatment expressed some regret. ${ }^{5}$ The respective treatment difference is not significant (MannWhitney, $p=0.5445)$. All other participants explicitly stated that they would like to use their strategies again. This indicates to us that the reliability of our data is high.

In the remainder of this section we subsequently describe the contributions on the induced paths $\left\{c_{t}^{i}\right\}_{t \geq 0}$ in Subsection 3.1, the results on initial contributions $c_{0}^{i}$ in Subsection 3.2 and the dynamic responses $\varphi^{i}(\bar{c})$ in Subsection 3.3. In Subsection 3.4 we will account for heterogeneity among our participants and in Subsection 3.5 we will provide some more evidence from the post-experimental questionnaire. All individual decisions are displayed in the graphs in Appendices A and B.

\subsection{Simulations of induced paths}

One advantage of our design is, as mentioned before, that all our observations are independent. Hence we can use them to simulate the induced path under all possible matching constellations and thus largely control for path dependence. It has been shown that heterogeneity among the participants can create a fair amount of path dependence which is hard to control for using conventional designs (see e.g., Palfrey and Prisbrey, 1996).

To exploit this advantage in our design we simulated the induced path of contributions over 20 periods for each of the possible 10,626 groups as if the members of this group are interacting as partners. Figure 1 displays for both treatments for each period the five interesting quantiles over the group contributions. Despite the absence of an endgame effect (due to the use of the random ending rule and our strategy method), these paths look qualitatively much like what has been found in previous literature. ${ }^{6}$

The median contribution in the Partner treatment starts at 6.75 , drops to 6.50 in one period and remains constant in the remaining periods. For the Stranger treatment the median contribution starts at 5.75 , drops to 1.75 within five interactions and remains at this level in later periods. The difference in the average contributions between the Partner and Stranger treatment is slightly smaller with contribution levels at 6.15 and 2.75 respectively, but nevertheless still substantial.

There are two additional properties worth noting. First, the .75 quantile in the Stranger treatment and the .25 quantile in the Partner treatment remain close to a contribution of 4.25 after the fifth period. This indicates that where $75 \%$ of the induced paths (group combinations) have contributions not below this level in the Partner treatment, an equal share of the induced paths (group combinations) have contributions not above this level in the Stranger treatment. Second, the .025 and .975 quantiles show that for the Partner treatment

\footnotetext{
${ }^{5}$ Out of those $29 \%$ (37\%) many participants expressed 'minor' regret with statements such as "Yes I would allocate a little more on screen one. I allocated 7, now I would allocate 9", "Only some small differences", and just "Maybe".

${ }^{6}$ See the references mentioned in the introduction.
} 


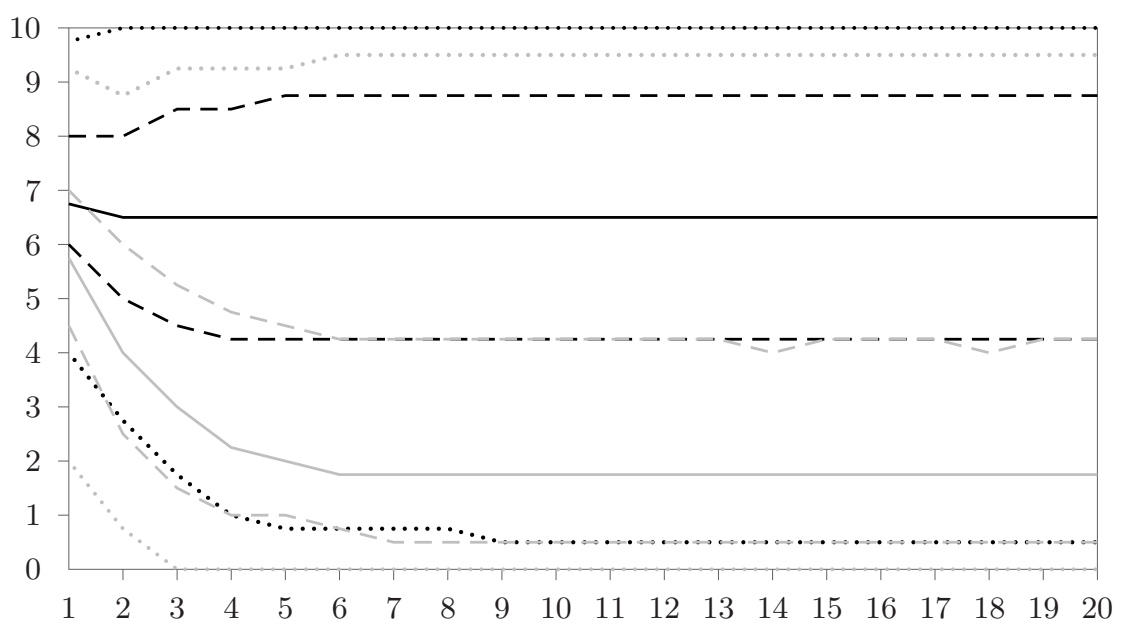

Figure 1: Quantiles for the Partner (black) and Stranger (grey) treatment. The solid line depicts the median; the dashed lines the .75 and .25 quantiles; the dotted lines the .025 and 0.975 quantiles.

contributions go down to zero in less than $2.5 \%$ of the cases and go up to full contribution in less than $2.5 \%$ of the cases in the Stranger treatment.

Overall we can conclude that contributions on the induced path are much higher in the Partner than in the Stranger treatment and that this is so irrespective of the particular matching realized in the experiment.

Observation 1. Contributions tend to be larger in a Partner treatment than in the Stranger treatment.

\subsection{Initial contribution}

The average initial contribution in the Partner treatment was 6.92 tokens and 5.71 in the Stranger treatment. Figure 2 shows the cumulative distribution of initial contributions for the two treatments. The distribution of the Partner treatment first-order stochastically dominates that of the Stranger treatment.

Although Figure 2 indicates a clear difference between initial contributions in the Partner and Stranger treatment, a Mann-Whitney test $(p=0.2384$, two-sided $)$ does not provide evidence for this difference to be statistically significant at conventional significance levels. This insignificance might be caused by the high variance in the observations.

Observation 2. Initial contributions are larger in the Partner treatment than in the Stranger treatment. 


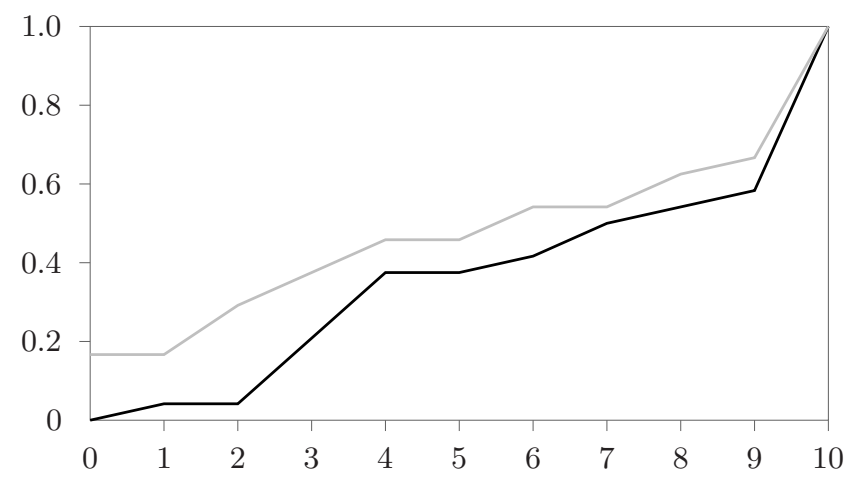

Figure 2: Cumulative distribution of initial contributions for the Partner (black) and Stranger (grey) treatment.

\subsection{Dynamic response behavior}

In order to analyze the dynamic responses, we ran the following simple OLS regression with random effects: ${ }^{7}$

$$
\varphi^{i}(\bar{c})=\alpha+\beta * \bar{c}+\delta_{S}+\delta_{S} * \bar{c}+\varepsilon^{i},
$$

where $\delta_{S}$ is a treatment dummy taking the value 1 in the Stranger treatment and 0 in the Partner treatment. The coefficient on the interaction term $\delta_{S} * \bar{c}$ turned out not to be significant and hence could be dropped from the final regression. This indicates that participants did not react significantly more strongly to others' contributions in the previous round in the Partner treatment than in the Stranger treatment (nor vice versa). The last term $\varepsilon^{i}$ captures the noise.

\begin{tabular}{|c|c|c|c|c|}
\hline \multicolumn{5}{|c|}{ dependent variable: contribution $\left(c_{t}^{i}\right)$} \\
\hline & coefficient & $p$-value & $95 \%$ con & ace interval \\
\hline const. & 2.2301 & 0.000 & 1.3151 & 3.1451 \\
\hline $\bar{c}_{t-1}$ & 0.6085 & 0.000 & 0.5545 & 0.6626 \\
\hline$\delta_{S}$ & -1.7689 & 0.005 & -3.0053 & -0.5326 \\
\hline
\end{tabular}

Table 1: OLS regressions on response behavior.

The regression results in Table 1 show that contributions are strictly increasing in the average contributions of the previous period and that participants contributed significantly more in the Partner than in the Stranger treatment. Figure 8 in Appendix $\mathrm{C}$ shows that irrespective of the initial contributions, the induced path converges to everyone contributing roughly 5.7 in the Partner treatment and 1.7 in the Stranger treatment if everyone were behaving according to the regression outcome above.

\footnotetext{
${ }^{7}$ Figure 7 in Appendix $\mathrm{C}$ indicates that linearity is a plausible assumption. Nevertheless, we also ran a quadratic model, which did not result a substantially better fit, neither were the quadratic coefficients significant.
} 
Next we will have a look at the dynamic responses on the individual level. Inspired by Fischbacher et al. (2001) and Fischbacher and Gächter (forthcoming) we relate the mean dynamic response contribution to the slope of the dynamic response for each participant separately. The mean is given by $\mu^{i}=\frac{1}{11} \sum_{\bar{c}=0}^{10} \varphi^{i}(\bar{c})$ and the slope by $\beta^{i}$ as estimated in the following regression separately for each participant: $\varphi^{i}(\bar{c})=\alpha^{i}+\beta^{i} * \bar{c}+\varepsilon^{i}$.

A Mann-Whitney test indicates that while the distribution of mean responses $\mu^{i}$ is significantly different across the two treatments $(p=0.0549)$, the estimated slopes $\beta^{i}$ do not differ significantly between the two treatments $(p=0.4073)$. These two findings are consistent with the earlier findings from the regression.

The cumulative distribution of the mean dynamic responses $\mu^{i}$ is shown in Figure 3. The

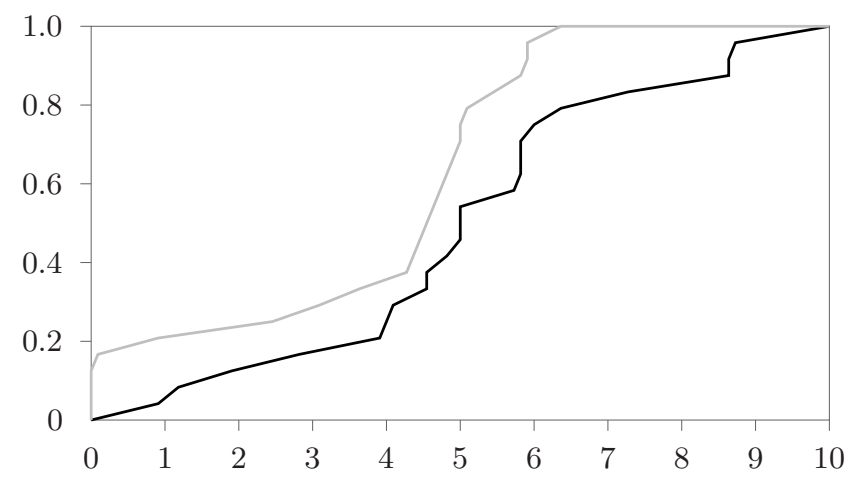

Figure 3: Cumulative distribution of mean response contributions for the Partner (black) and Stranger (grey) treatment.

mean contribution in the Partner treatment first-order stochastically dominates that of the Stranger treatment. In addition, Table 2 shows that in the Partner treatment there is a higher (smaller) intensity to contribute above (below) the previous average contribution than in the Stranger treatment.

\begin{tabular}{lrrrrrrrrrrrr}
\hline & \multicolumn{10}{c}{ previous average by others } & \\
\cline { 2 - 11 } response & 0 & 1 & 2 & 3 & 4 & 5 & 6 & 7 & 8 & 9 & 10 & sum \\
\hline$>$ & 14 & 11 & 12 & 13 & 14 & 11 & 13 & 12 & 11 & 10 & 0 & 121 \\
$=$ & 10 & 6 & 5 & 3 & 3 & 5 & 3 & 3 & 4 & 5 & 16 & 63 \\
$<$ & 0 & 7 & 7 & 8 & 7 & 8 & 8 & 9 & 9 & 9 & 8 & 80 \\
\hline$>$ & 9 & 10 & 7 & 5 & 6 & 6 & 6 & 6 & 5 & 6 & 0 & 66 \\
$=$ & 15 & 3 & 6 & 6 & 7 & 5 & 5 & 5 & 7 & 4 & 8 & 71 \\
$<$ & 0 & 11 & 11 & 13 & 11 & 13 & 13 & 13 & 12 & 14 & 16 & 127 \\
\hline
\end{tabular}

Table 2: Intensity to contribute above/equal/below the previous group average for the Partner (first block) and Stranger (second block) treatment.

Finally, Figure 4 depicts the resulting $\left(\mu^{i}, \beta^{i}\right)$-pairs for each individual. The left panel displays the Partner treatment; the right panel the Stranger treatment. We see that where for the Stranger treatment there is a strong correlation between the mean and the slope 
(Spearman test, $\rho=0.5462, p=0.0058$ ), there is not such a clear correlation in the Partner treatment (Spearman test, $\rho=-0.0856, p=0.6909$ ). In other words, those participants that contribute more in the Stranger treatment tend to also react more strongly to their opponents' contributions, while in the Partner treatment there is no such relation.
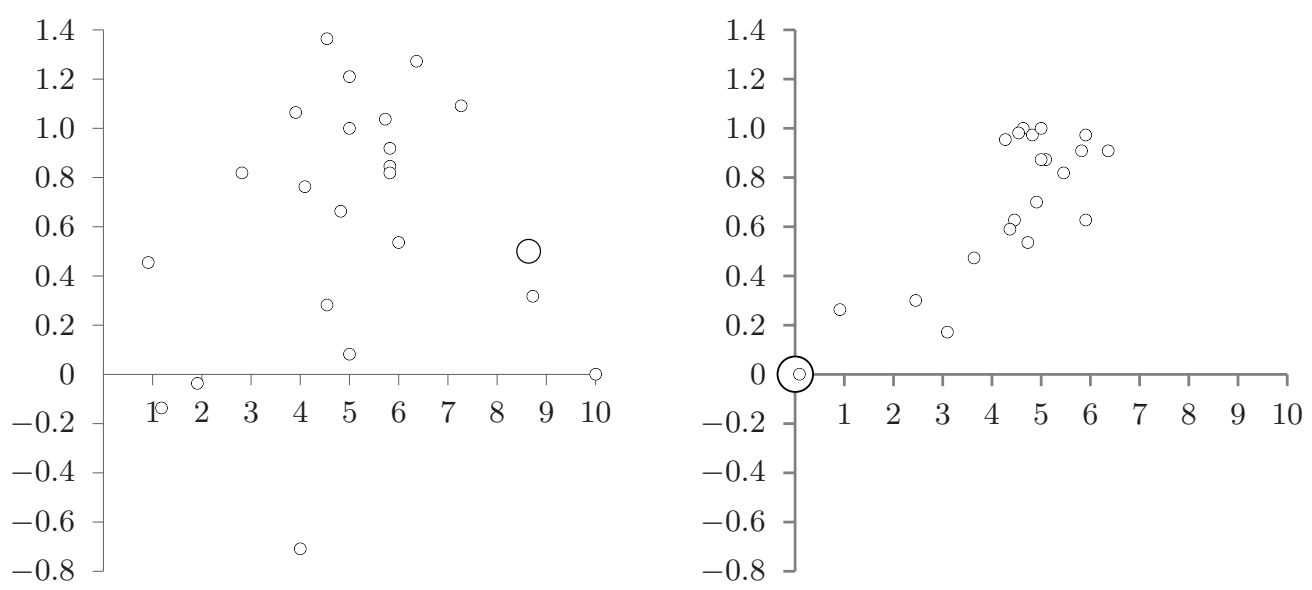

Figure 4: Mean vs. slope of dynamic response behavior for the Partner (left) and Stranger (right) treatment.

Observation 3. Mean response contributions are significantly higher in the Partner than in the Stranger treatment. There is no significant treatment difference in the slopes of the dynamic responses.

\subsection{Categorization}

We categorize our participants into six categories, according to whether they provide a 'high' $(>5)$ or 'low' $(<5)$ initial contribution and whether their dynamic response is upward sloping, flat at zero or of any other shape. We classify a dynamic response as 'upward sloping' whenever the $95 \%$ confidence interval for $\beta^{i}$ is strictly above zero and the $\mathrm{p}$-value for $\beta^{i}$ below $1 \%$ level. ${ }^{8}$ A 'free rider' never contributes more than 2 units. Table 3 and 4 provide an overview of the sizes of the categories in our two treatments.

\begin{tabular}{lcccc}
\hline initial & \multicolumn{3}{c}{ dynamic response } & \\
\cline { 2 - 4 } contribution & upward sloping & free rider & other & total \\
\hline high & $50.0 \%$ & - & $12.5 \%$ & $62.5 \%$ \\
low & $16.7 \%$ & - & $20.8 \%$ & $37.5 \%$ \\
\hline total & $66.7 \%$ & - & $33.3 \%$ & $100.0 \%$ \\
\hline
\end{tabular}

Table 3: Categorization of participants in the Partner treatment.

Most participants rely on increasing strategies in our experiment (two-thirds of all participants, irrespective of the treatment). These strategies are reminiscent of what is often

\footnotetext{
${ }^{8}$ Individual regression tables can be provided upon demand.
} 


\begin{tabular}{lcccc}
\hline initial & \multicolumn{3}{c}{ dynamic response } & \\
\cline { 2 - 4 } contribution & upward sloping & free rider & other & total \\
\hline high & $41.7 \%$ & $4.2 \%$ & $8.3 \%$ & $54.2 \%$ \\
low & $25.0 \%$ & $20.8 \%$ & - & $45.8 \%$ \\
\hline total & $66.7 \%$ & $25.0 \%$ & $8.3 \%$ & $100.0 \%$ \\
\hline
\end{tabular}

Table 4: Categorization of participants in the Stranger treatment.

called 'conditional cooperation' in the literature. ${ }^{9}$ The categorization found in the Stranger treatment is perfectly consistent with the results obtained by Keser and van Winden (2000), Fischbacher et al. (2001) and Fischbacher and Gächter (forthcoming). Treatment differences emerge in the number of free-riders, which is $25 \%$ in the Stranger treatment and zero in the Partner treatment (Mann-Whitney, $p<0.0001$ ) and in the number of participants that use a high initial contribution (Mann-Whitney, $p=0.2348$ ).

Observation 4. Irrespective of the treatment, most participants (two-thirds) use upward sloping strategies. In the Partner treatment there are significantly less free riders than in the Stranger treatment.

\subsection{Questionnaire Data}

In this subsection we report some selective evidence from our post-experimental questionnaire on gender differences and treatment differences in 'norm perception'. ${ }^{10}$

Gender 24 men and 24 women participated in our experiment. There were 14 women in the Stranger treatment and 10 women in the Partner treatment. A binomial test cannot reject the hypothesis that our sample is gender balanced for either of our treatments ( $p=0.4167)$. We find that men make significantly higher initial contributions than women (Mann-Whitney, $p=0.0011$ ), but mean conditional contributions are not significantly different across genders (Mann-Whitney, $p=0.2877$ ), neither is the slope of contributions (Mann-Whitney, $p=0.0816$ ). Initial contributions of men are on average $8.4 / 7.6$ with a standard deviation of 2.3/3.2 for the Partner/Stranger treatment, while women contribute on average 5.0/4.4 initially with a standard deviation of 3.2/3.9.

Norm perception An interesting treatment difference arises when we look at norm perceptions. We confronted the participants with eight statements out of which we highlight the

\footnotetext{
${ }^{9}$ See Keser and van Winden (2000), Fischbacher et al. (2001), Fischbacher and Gächter (forthcoming) or Grimm and Mengel (2009).

${ }^{10}$ The full questionnaire is available upon request.
} 
following four: ${ }^{11}$

S3: Allocating a lot to [the public good] makes me feel good!

S4: Allocating less than my (former) group members to [the public good] makes me feel bad!

S5: Allocating a lot to [the public good] is a sign of intelligence.

S6: Allocating little to [the public good] is a sign of intelligence.

Participants had to evaluate these statements on a scale of 1 (totally agree) to 7 (totally disagree). Table 5 shows the mean level of agreement to each statement in the two treatments with the standard deviation in parentheses.

\begin{tabular}{lcccc}
\hline & S3 & S4 & S5 & S6 \\
\hline Partner & $3.33(0.36)$ & $4.00(0.35)$ & $2.70(0.30)$ & $5.33(0.20)$ \\
Stranger & $3.58(0.38)$ & $4.38(0.41)$ & $3.38(0.40)$ & $4.20(0.34)$ \\
\hline
\end{tabular}

Table 5: Levels of agreement (scale 1-7) to the statements.

The first thing to notice are the treatment differences in the reactions to statements S6 and S5. In the Partner treatment participants agree much more to the statement that allocating a lot to the public good is a sign of intelligence (Mann-Whitney, $p=0.0623$ ), whereas they agree much less to the statement that contributing little is a sign of intelligence (Mann-Whitney, $p<0.0001)$. Furthermore, while the level of agreement to the more emotional statements S3 and S4 does not differ much from that of S5 and S6 in the Stranger treatment, in the Partner treatment participants show significantly higher levels of agreement to statement S5 than to any other statement (including the four statements not further discussed here) and lower levels of agreement to statement S6 than to any other statement.

\section{Discussion}

It is a by now common finding in experiments on repeated public good games that subjects' behavior differs from the game theoretic predictions of subgame perfection and also often Nash equilibrium. This raises the question whether subjects recognize the strategic implications of a repeated game situation compared to a one-shot (or random matching) situation. Experimentalists have tried to induce this difference in the lab via 'Partner' and 'Stranger' designs and have found mixed results.

In this experimental study, we have explored the difference between these two matching protocols in an environment that excludes learning and explicit reputation building. We found that even in such an environment there are significant differences, suggesting that neither explicit reputation building, nor emotions, nor learning are the sole determinants of the difference between partner and stranger matchings. ${ }^{12}$

\footnotetext{
${ }^{11}$ In the experiment we called the public good 'project $\mathrm{Y}$ '.

${ }^{12}$ Of course any of these could exacerbate the effects we have already found in this 'cold' setting in a more
} 
The fact that two-thirds of all subjects use conditional (upward sloping) strategies together with the fact that there are significantly more free-riders in the stranger treatment suggests that subjects are well aware of the strategic implications of the partner/stranger design. In other words, they seem to be able to distinguish well between one-shot and repeated situations.

The observed patterns are partly consistent with a theory of reciprocity, since in the stranger treatment there are less ways to effectively implement reciprocity. There are two elements, though, which suggests that such a theory requires at least some agents to be strategic. Reciprocity can explain the data only if (a) some 'free-riders' are strategic enough to anticipate reciprocity in the partner treatment and hence refrain from contributing nothing and (b) some agents provide higher initial contributions strategically anticipating reciprocity. Also the fact that the slope of the dynamic responses is not higher in the partner than in the stranger treatment suggests that reciprocity is not the driving force behind our treatment differences.

The evidence found in the questionnaire seems to confirm our overall impression that participants realized the strategic implications of the implemented matching protocol. In the partner treatment they state significantly higher levels of agreement to 'rational motives' rather than 'emotional motives' and they agree much more to the statement that contributing is an 'intelligent' thing to do.

In sum, we found significant differences in contributions between a partner and stranger design which can be explained only if a significant amount of agents are strategic. Our participants seem to recognize the strategic implications of repeated interaction versus a random matching scenario and they do treat these situations as fundamentally different. This obviously need not imply that they play Nash equilibrium, since they might differ in their levels of rationality as well as priors about others. Finally, in less 'cold' designs other effects (like emotions, reputation building, etc.) may come into play, which could make the observed treatment differences even stronger. Our design enables us, though, to conclude that strategic considerations are an important determinant for behavior in repeated public good games.

\section{References}

1. Andreoni J (1988). Why free ride? Strategies and learning in public goods experiments. Journal of Public Economics 37 (3): 291-304.

2. Anderoni J and R Croson (2008). Partners versus strangers: Random rematching in public goods experiments. Handbook of Experimental Economics Results, Volume 1: 776-783.

'hot' environment. The literature that has been using such designs, though, does not find stronger treatment differences than we do. 
3. Brandts J and G Charness (2000). Hot vs. cold: Sequential responses and preference stability in experimental games. Experimental Economics 2 (3): 227-238.

4. Croson R (1996). Partners and strangers revisited. Economics Letters 53 (1): 25-32.

5. Duffy J and J Ochs (2009). Cooperative behavior and the frequency of social interaction. Games and Economic Behavior 66 (2): 785-812

6. Fischbacher U (2007). z-Tree: Zurich toolbox for ready-made economic experiments. Experimental Economics 10 (2): 171-178.

7. Fischbacher U, S Gächter and E Fehr (2001). Are people conditionally cooperative? Evidence from a public goods experiment. Economics Letters 71 (3): 397-404.

8. Fischbacher U and S Gächter (forthcoming). Social preferences, beliefs and the dynamics of free riding in public good experiments. American Economic Review.

9. Grimm V and F Mengel (2009). Cooperation in viscous populations - Experimental evidence. Games and Economic Behavior 66 (1), 202-220.

10. Keser C (2000). Strategically planned behavior in public goods experiments. Working paper: Cirano 2000s-35.

11. Keser $\mathrm{C}$ and $\mathrm{F}$ van Winden (2000). Conditional cooperators and voluntary contributions to public goods. Scandinavian Journal of Economics 102 (1): 23-39.

12. Palfrey T and J Prisbrey (1996). Altruism, reputation, and noise in linear public goods experiments. Journal of Public Economics 61 (3): 409-427.

13. Reuben E and S Suetens (2009). Revisiting strategic versus non-strategic cooperation. Working paper: CentER Discussion Paper No. 2009-22.

14. Selten R (1967). Die Strategiemthode zur Erforschung des eingeschränkt rationalen Verhaltens im Rahmen eines Oligopolexperimentes. In: H Sauermann (ed.) Beiträge zur experimentellen Wirtschaftsforschung. Tübingen: J.C.B. Mohr (Paul Siebeck), pp. 136-168.

15. Sonnemans J, A Schram and T Offerman (1999). Strategic behavior in public good games: When partners drift apart. Economics Letters 62 (1): 35-41.

16. Weimann J (1994). Individual behavior in a free riding experiment. Journal of Public Economics 54 (2): 185-200. 


\section{A Partner}
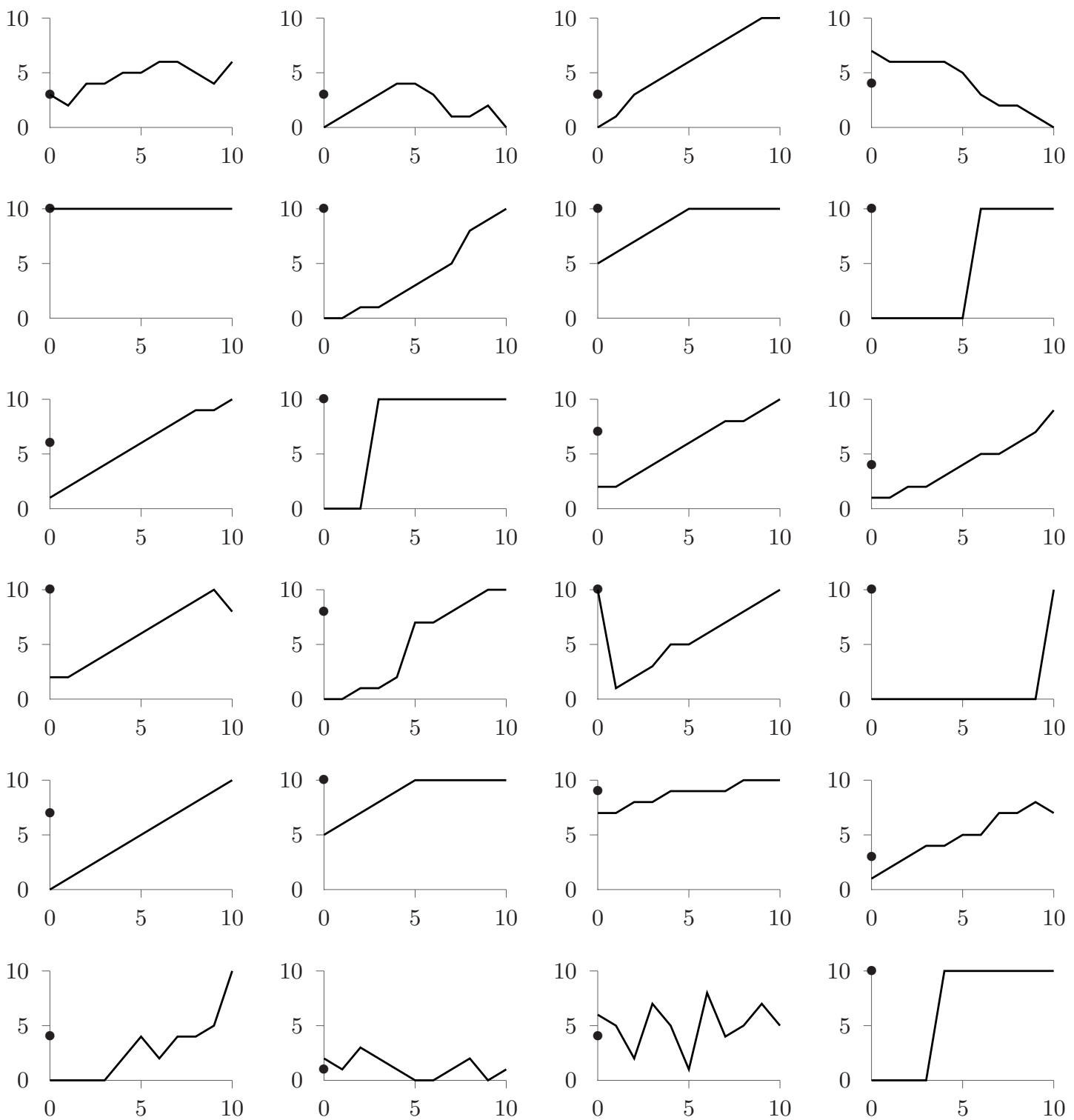

Figure 5: Individual decisions by the 24 participants in the Partner treatment. 


\section{B Stranger}
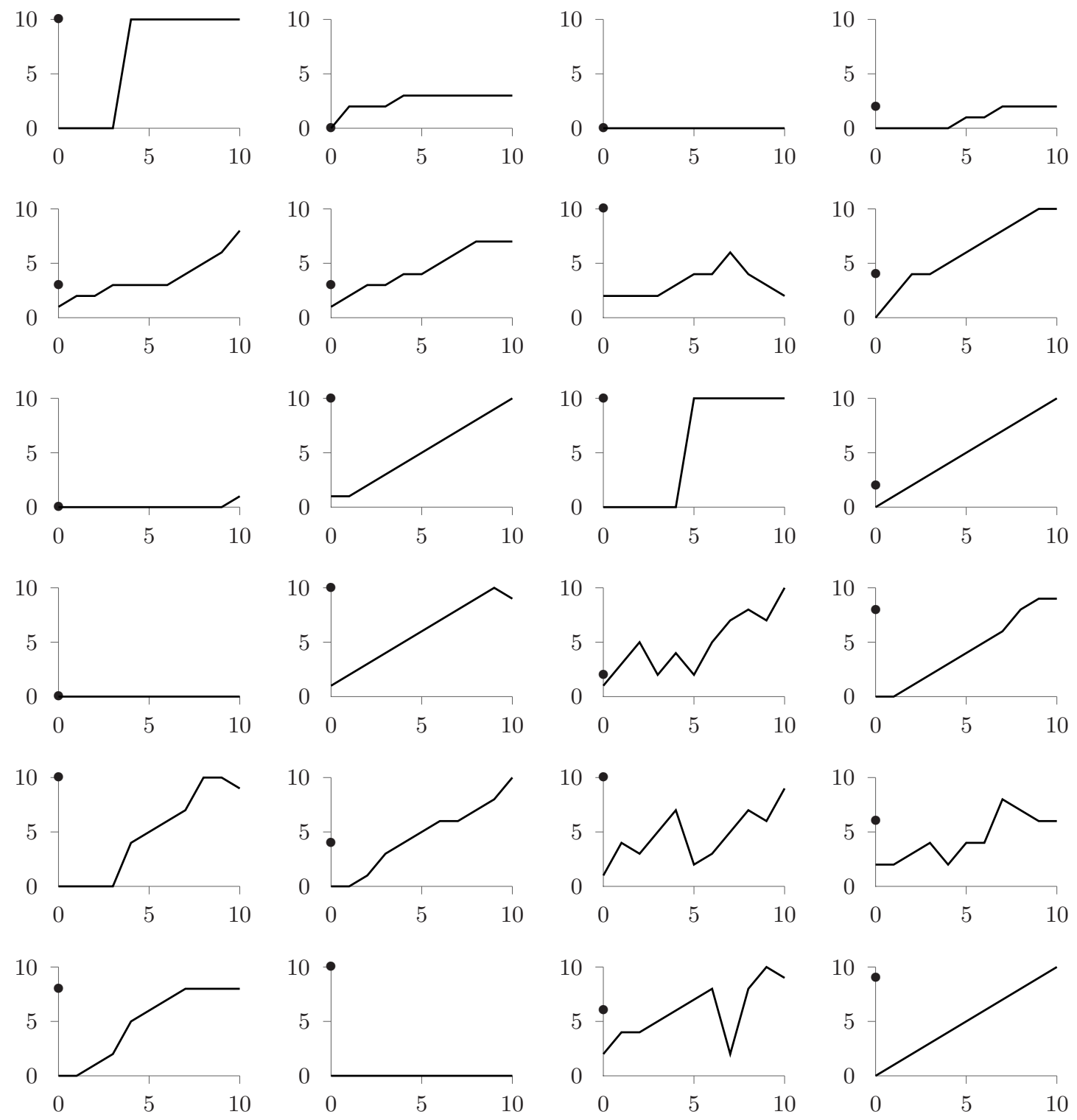

Figure 6: Individual decisions by the 24 participants in the Stranger treatment. 


\section{Partner vs. stranger}

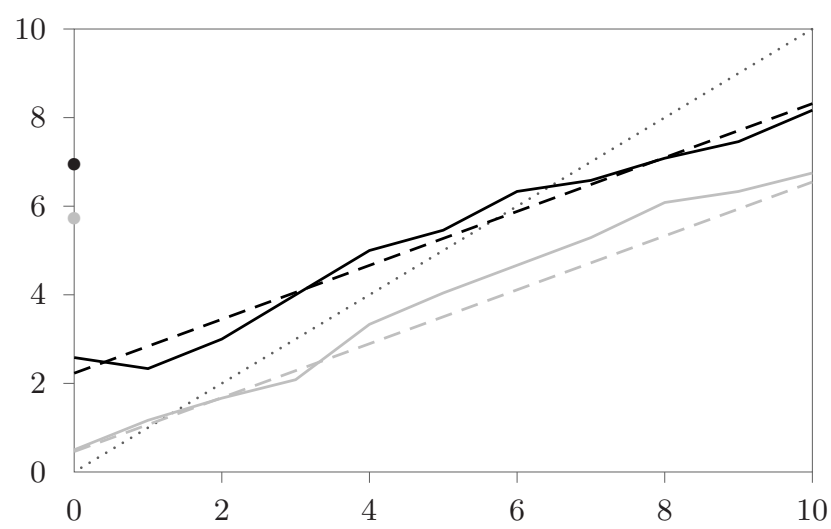

Figure 7: Average decisions by the 24 participants in the Partner (black) and Stranger (grey) treatment. The dashed lines illustrate the regression outcome.

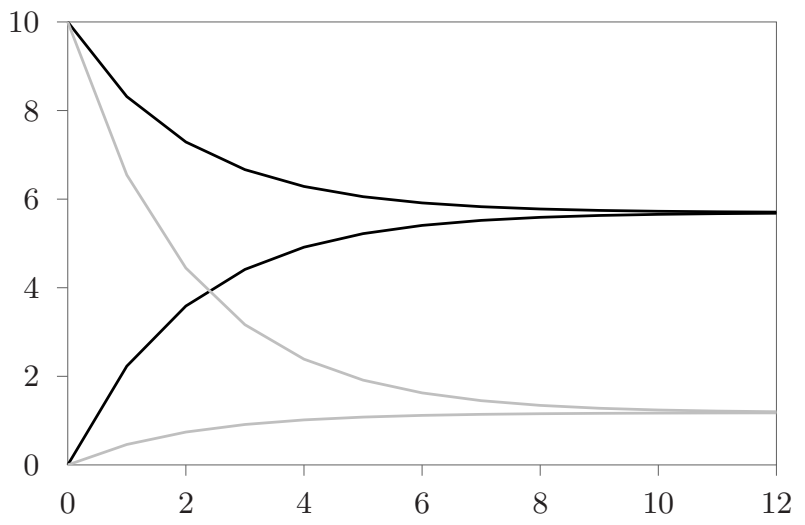

Figure 8: Convergence of contributions over time if everyone were having the regression estimate as dynamic response in the Partner (black) and Stranger (grey) treatment. 


\section{Instructions}

This appendix provides the written instructions as we used them in the Partner treatment. Apart from adding 'former' when referring to the group members in the previous period, the text for the Stranger treatment was similar.

\section{Welcome}

Dear participant,

Thank you for taking part in this experiment. It will last about 45-60 minutes.

These instructions are solely for your private information. It is important that you read them carefully. All other participants in this experiment receive identical instructions.

In order to ensure that the experiment takes place in an optimal setting, we want to ask you to follow the general rules during the whole experiment:

- Do not communicate with other participants!

- Do not forget to switch off your mobile phone!

- Read the instructions carefully. If something is not well explained or you have any question now or at any time during the experiment, then ask one of the experimenters. Do, however, not ask out loud, raise your hand instead. We will clarify questions privately.

- You may take notes on this instruction sheet if you wish.

- After the experiment, remain seated till we have paid you.

- If you do not obey the rules, the data becomes useless for us. Therefore, we will have to exclude you from this (and future) experiment(s) and you will not receive any compensation.

In addition to the $\mathbf{3}$ Euro participation fee you are compensated according to your performance. We will not speak of Euros during the experiment, but rather of ECU (Experimental Currency Units). At the end of the experiment, the total amount you have earned will be converted to Euro at the following rate:

\section{$1 \mathrm{ECU}=3$ Eurocents.}

The payment takes place in cash at the end of the experiment. Your decisions and earnings in this experiment will remain anonymous. 


\section{Situation}

Below we will explain the different decisions you can take in this experiment. First, though, we introduce you to the basic decision situation. You will find control questions that help you to understand the environment at the end of this paragraph.

You will be a member of a group consisting of 4 people. Each group member is endowed with 10 tokens and has to decide how to allocate these tokens between project $X$ and project $Y$. Each token allocated to project $X$ provides you with an income of 2 ECU. Each token allocated to project $Y$ generates an income of $4 \mathrm{ECU}$ which is equally shared among the four group members, i.e. gives an income of 1 ECU to each group member (including you). The same rule is applied to all other group members. Hence, you will also get 1 ECU for every token they allocate to project $Y$. Your income can be summarized by the following formula:

Your income $=$

$2 \times$ tokens that you allocate to project $X$

$+1 \times$ all tokens that are allocated to project $Y$ by all the group members 


\section{Control Questions 1}

Please answer the following control questions. They will help you to gain understanding of the calculation of your income, which varies with your decision about how to allocate the 10 tokens. Please answer all the questions and write down your calculations.

1. Assume none of the four group members (including you) allocates anything to project $Y$.

(a) What will your income be?

(b) What will be the income of each of the other group members?

2. Assume all of the four group members (including you) allocate all of their 10 tokens to project $Y$.

(a) What will your income be?

(b) What will be the income of each of the other group members?

3. Suppose that the other 3 group members allocate on average 5 tokens each to project $Y$.

(a) What will your income be, if you -in addition to the 15 tokens - allocate 1 token to project $Y$ ?

(b) What will your income be, if you-in addition to the 15 tokens - allocate 4 tokens to project $Y$ ?

(c) What will your income be, if you - in addition to the 15 tokens - allocate 7 tokens to project $Y$ ?

4. Suppose you allocate 4 tokens to project $Y$.

(a) What will your income be, if the other 3 group members -in addition to your 4 tokens - allocate on average $2 \frac{2}{3}$ tokens each to project $Y$ ?

(b) What will your income be, if the other 3 group members - in addition to your 4 tokens - allocate on average $5 \frac{1}{3}$ tokens each to project $Y$ ?

(c) What will your income be, if the other 3 group members - in addition to your 4 tokens - allocate on average 8 tokens each to project $Y$ ? 


\section{Duration}

The situation above will be repeated for an unknown number of periods. Every period there is a chance of $90 \%$ that the experiment continues with one more period. Hence, every period there is a chance of $10 \%$ that the experiment ends. ${ }^{13}$ This means that no matter in which period you are, in expectation, another 9 periods will follow. Your final income is the total of your incomes over all periods.

\section{Matching}

Before the first period, a central computer divides the participants randomly into groups of 4. Groups remain fixed throughout the entire session. The assignment process is random and anonymous, so you will not know who else is in your group. Apart from us - the experimenters - nobody else will ever learn the group compositions.

\section{Feedback}

After every period you are informed about the average number of tokens allocated to project $Y$ by your group members. Your period income follows directly from this information together with your own allocation decision.

\footnotetext{
${ }^{13} \mathrm{~A}$ central computer draws for each period a random number between 0 and 1 and the experiment will continue as long as the number drawn is less than 0.9. For every period the random draw is independent of previous draws.
} 


\section{Your decision}

In the experiment you are asked to make two decisions. The first decision is on the initial allocation of the 10 tokens between project $X$ and $Y$ in the first period. This decision (together with that of your group members) determines your income in the first period. For all subsequent periods you can (but need not) condition your allocation decision on the average allocation of tokens to project $Y$ by your group members in the previous period. This is why, in this experiment, you are asked to fill in two decision screens.

In the first decision screen you are asked to indicate your initial allocation (in integer amounts) of the 10 tokens between projects $X$ and $Y$ (see Screenshot 1).

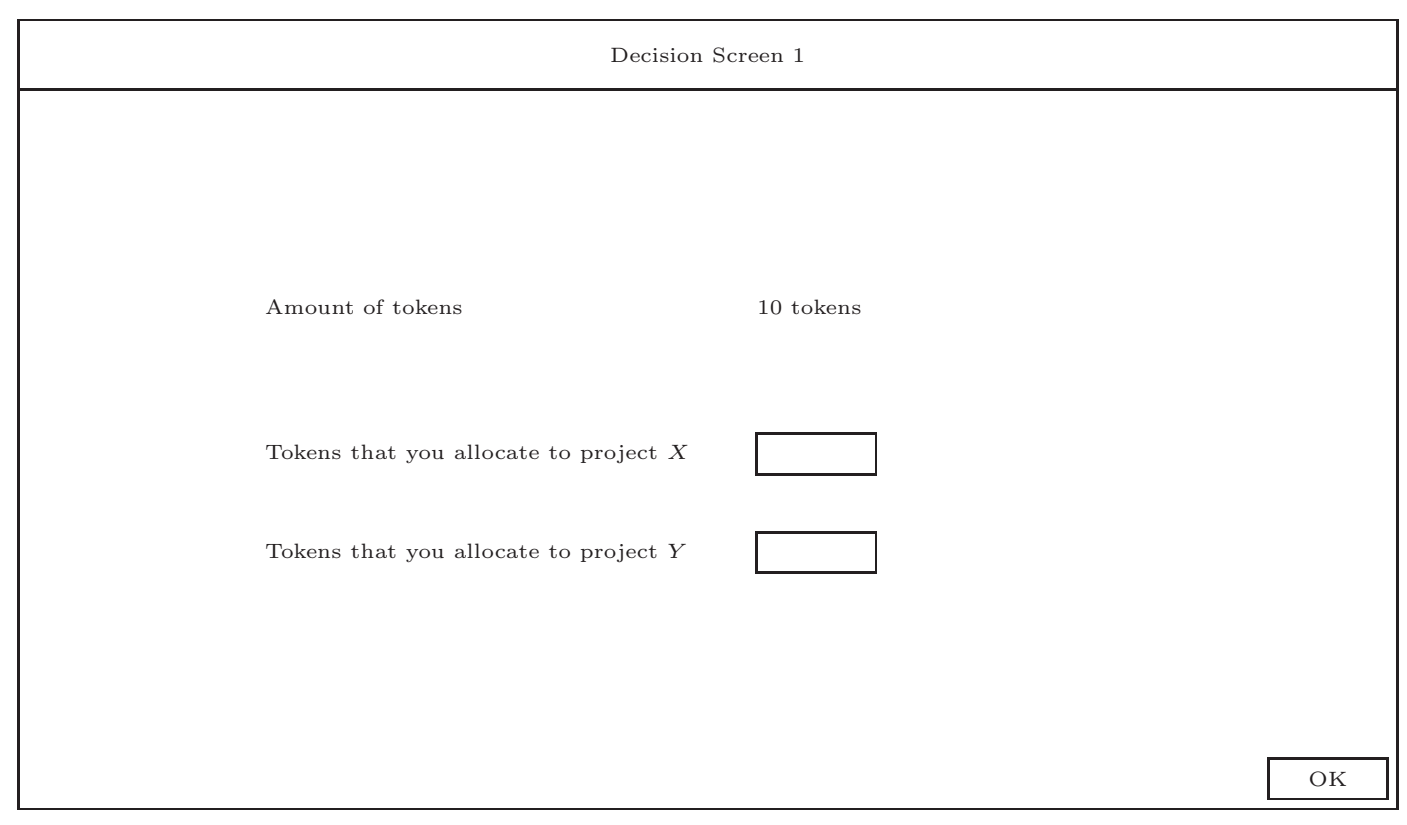

Screenshot 1 
In the second decision screen you are asked about your allocation in a period conditional on the average allocation of tokens to project $Y$ by your group members in the previous period (see Screenshot 2). This decision is a little more complicated than the first decision, since you will not know the average allocation of your group members at the time of filling in this decision screen. This is why you have to indicate your allocation of the 10 tokens conditional on all of their possible average allocations to project $Y$ rounded to the nearest integer.

The screen should be read as follows. In the first two cells you enter your allocation of the 10 tokens (in integer amounts) between project $X$ and project $Y$ when in the previous period the average allocation to project $Y$ by your group members was larger or equal to 0 but strictly less than 0.5. In the next two cells you enter your allocation of the 10 tokens when in the previous period the average allocation to project $Y$ by your group members was larger or equal to 0.5 but strictly less than 1.5 , and so on ....

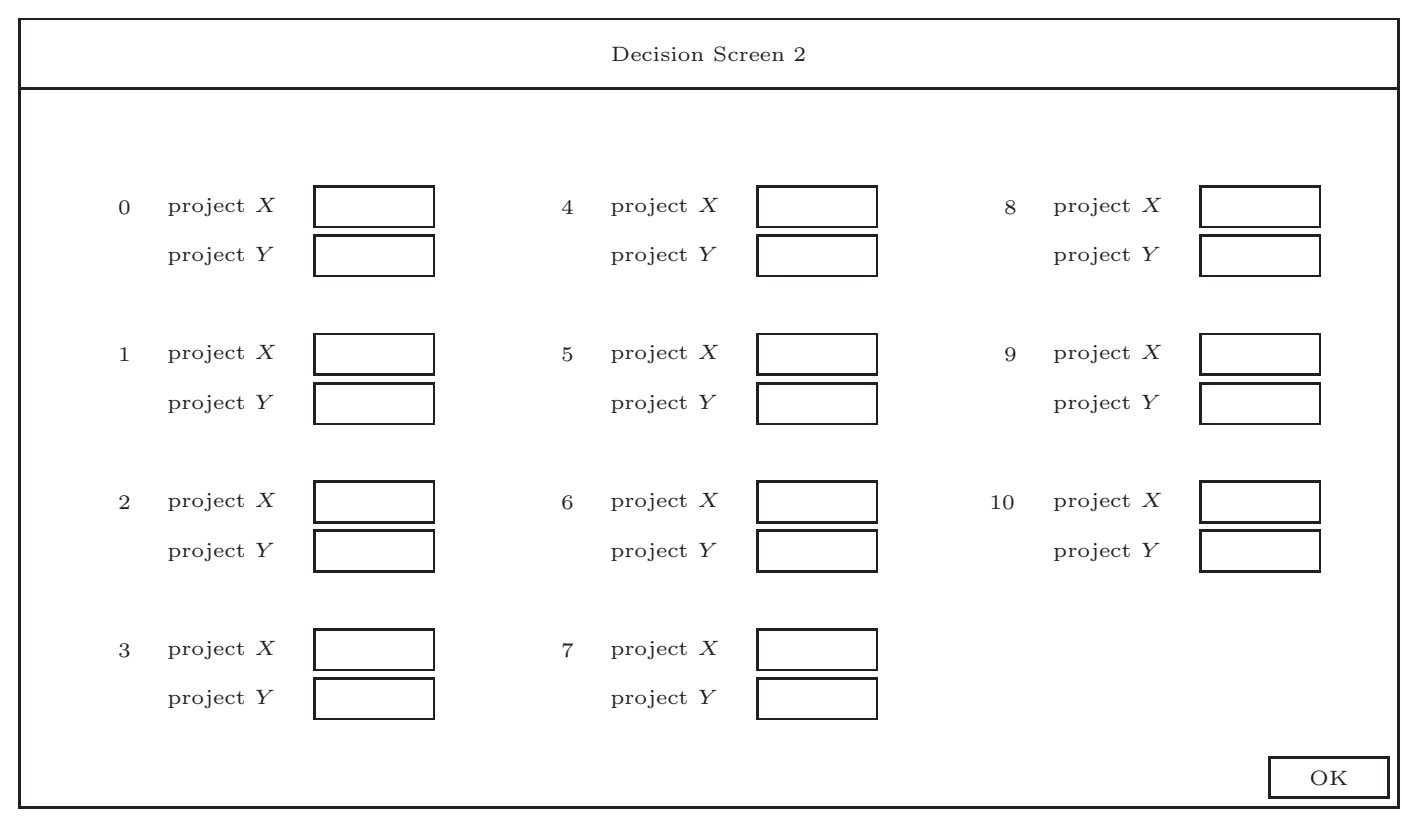

Screenshot 2

Keep in mind that all participants take the same two decisions. Neither you nor your group members will be able to change any of the two decisions during the experiment. Hence, your decisions in the second decision screen will be used to compute your allocation in all periods (except the first) of the experiment. This also applies to your group members. 


\section{Result}

Next, the experiment will be simulated on basis of these two decisions taken by all group members. That is, for each group member the decision in the first decision screen applies for the first period. Every following period the decision of each group member is determined by the choices that are made in the second decision screen.

For clarification:

1. Your allocation for the first period is simply your initial allocation that you have chosen in the first decision screen. The same holds for all your group members.

2. To determine your allocation in the second period, the average of your group members' initial allocations to project $Y$ is computed. Your allocation is then determined by the corresponding entry you made in the second decision screen. The same is done for all your group members.

3. To determine your allocation in the third period, the average of your group members' allocations to project $Y$ in the second period (see step 2) is computed. Your allocation is then determined by the corresponding entry you made in the second decision screen. The same is done for all your group members.

4. To determine your allocation in the fourth period, the average of your group members' allocations to project $Y$ in the third period (see step 3) is computed. Your allocation is then, again, determined by the corresponding entry you made in the second decision screen. The same is done for all your group members.

5. ... [this procedure continues until the final (but unknown) period.]

This means that:

- Your (initial) allocation can affect future allocations by your group members in all periods of the experiment.

- Vice versa, (initial) allocations by your other group members can affect your future allocations in all periods of the experiment.

Hence, you should take both of your decisions very carefully. 


\section{Feedback}

For each period you receive feedback on all income relevant information (see Screenshot 3). That is, for each period, you receive feedback on your allocation to project $Y$ and the average allocation to project $Y$ by your group members. Both numbers determine your period income. The second number (together with your choices in the second decision screen) influences your next period allocation. Whether a next period follows is based on the random draw by a central computer.

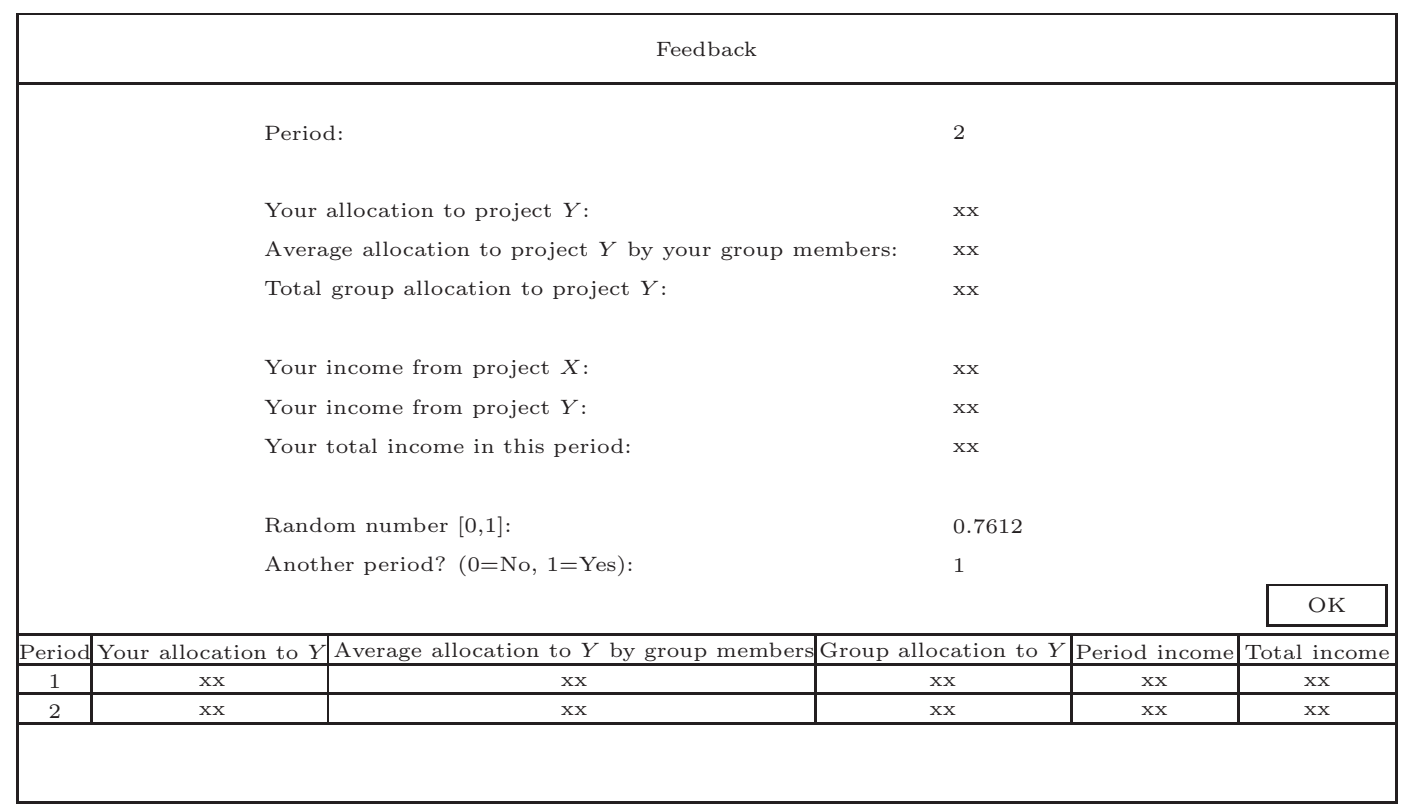

Screenshot 3 


\section{Control Questions 2}

Please answer the following control questions. They will help you to gain understanding of how decisions affect final allocations over periods. Please write down your answers to these questions. Notice that all numbers used are chosen arbitrary.

1. Suppose that all group members (including you) have chosen an initial allocation of 2 tokens to project $Y$ and the following conditional allocations to project $Y$ :

\begin{tabular}{llrr}
\hline $0 \longrightarrow 1$ & $4 \longrightarrow 7$ & $8 \longrightarrow 7$ \\
$1 \longrightarrow 4$ & $5 \longrightarrow 2$ & $9 \longrightarrow 10$ \\
$2 \longrightarrow 3$ & $6 \longrightarrow 8$ & $10 \longrightarrow 9$ \\
$3 \longrightarrow 1$ & $7 \longrightarrow 9$ & & \\
\hline
\end{tabular}

(a) What will be each group member's allocation to project $Y$ in the second period?

(b) What will be each group member's allocation to project $Y$ in the third period?

(c) What will be each group member's allocation to project $Y$ in the fourth period?

(d) What will be each group member's allocation to project $Y$ in the fifth period?

2. Suppose that all group members (including you) have chosen an initial allocation of 8 tokens to project $Y$ and the following conditional allocations to project $Y$ :

\begin{tabular}{llr}
\hline $0 \longrightarrow 1$ & $4 \longrightarrow 7$ & $8 \longrightarrow 6$ \\
$1 \longrightarrow 0$ & $5 \longrightarrow 5$ & $9 \longrightarrow 9$ \\
$2 \longrightarrow 0$ & $6 \longrightarrow 2$ & $10 \longrightarrow 8$ \\
$3 \longrightarrow 2$ & $7 \longrightarrow 9$ & \\
\hline
\end{tabular}

(a) What will be each group member's allocation to project $Y$ in the second period?

(b) What will be each group member's allocation to project $Y$ in the third period?

(c) What will be each group member's allocation to project $Y$ in the fourth period?

(d) What will be each group member's allocation to project $Y$ in the fifth period? 
3. Suppose that all group members (including you) have chosen an initial allocation of 6 tokens to project $Y$ and the following conditional allocations to project $Y$ :

\begin{tabular}{llr}
\hline $0 \longrightarrow 5$ & $4 \longrightarrow 7$ & $8 \longrightarrow 4$ \\
$1 \longrightarrow 6$ & $5 \longrightarrow 5$ & $9 \longrightarrow 5$ \\
$2 \longrightarrow 7$ & $6 \longrightarrow 4$ & $10 \longrightarrow 3$ \\
$3 \longrightarrow 4$ & $7 \longrightarrow 5$ & \\
\hline
\end{tabular}

(a) What will be each group member's allocation to project $Y$ in the second period?

(b) What will be each group member's allocation to project $Y$ in the third period?

(c) What will be each group member's allocation to project $Y$ in the fourth period?

(d) What will be each group member's allocation to project $Y$ in the fifth period?

4. Indicate for each of the statements whether they are true or false.

\begin{tabular}{lcc}
\hline Statement & True & False \\
\hline $\begin{array}{l}\text { Each period my group members are the same as in the previous } \\
\text { period! }\end{array}$ & $\square$ & $\square$ \\
The chance that the experiment ends is larger in later periods! & $\square$ & $\square$ \\
All relevant decisions are made before feedback is received! & $\square$ & $\square$ \\
The initial allocation potentially affects all periods; even if the & & \\
game has very many! & $\square$ \\
$\begin{array}{l}\text { My initial allocation is not relevant for the allocations of my } \\
\text { group members in the second period! }\end{array}$ & $\square$ \\
$\begin{array}{l}\text { I know my group members' initial allocations before I fill in the } \\
\text { second decision screen! }\end{array}$ & $\square$ \\
$\begin{array}{l}\text { My conditional allocations are not relevant for the allocations of } \\
\text { my group members in the third period! }\end{array}$ & $\square$ \\
$\begin{array}{l}\text { My group members, in principle, have the same influence on my } \\
\text { income as I have on theirs! }\end{array}$ & $\square$ \\
\hline
\end{tabular}

